\title{
3D Modeling, Simulation and Analysis of Anti-Vibration Boring Bar
}

\author{
Sabi Sabev \\ Technical University - Sofia, Plovdiv Branch \\ Plovdiv, Bulgaria \\ sabi_sabev@tu-plovdiv.bg
}

\author{
Plamen Kasabov \\ Technical University - Sofia, Plovdiv Branch \\ Plovdiv, Bulgaria \\ kasabov_p@abv.bg
}

\begin{abstract}
This study presents the capabilities of the engineering dynamic analysis according to the Finite Elements Method (FEM), demonstrated on a 3D virtual prototype of a part "Anti-vibration boring bar" for lathe. The analysis is performed with help of CAE system Ansys. The modal frequencies are determined which are necessary for optimizing the constructive parameters of the product during the design stage.
\end{abstract}

Keywords - boring bar, FEM, modal frequencies, virtual prototype.

\section{INTRODUCTION}

In practice in the production of parts with deep holes (e.g., deep $>5 x D$ ) usually select a boring process to achieve the desired dimensional accuracy when dealing with cases of large holes as an alternative approach to the conventional drilling and surface finishing.

Finished surface quality and dimensional accuracy of high-precision mechanical parts produced by machining processes are greatly affected by the static and dynamic behaviour of the machining system. Inadequate cutting parameters or machining system compliance may give rise to undesired vibration arising during the cutting process, which is degrade quality for surface finish and dimensional accuracy. The long work in conditions of vibrations of a boring bar may cause premature tool wear or tool breakage, and damage to machine tool elements such as tooling system or spindle bearings. It is desired to increase the dynamic stiffness of the boring bar by improving its damping properties. The damping is increased either actively [2], [3] or passively [4].

There have been many theoretical investigations regarding stable and unstable operating ranges for various cutting conditions. These works typically rely on constructing models and varying one parameter (cutting speed, width of cut, etc.) at a time in order to generate stability lobe diagrams showing regions of stable and unstable cutting [6].

Virtual engineering includes a wide range of engineering activities such as: analysis, simulations, optimizations, etc., related to both the design process (CAD) and the production process (CAM). Engineering analysis is a key element in making a 3D model.

One of the most common operations performed by CAE systems on a 3D prototype is Finite Element Analysis (FEA). This method is used as a universal tool for calculations and analysis of the behaviour of mechanical systems in power, heat and others. loads [1].

The main thing for this method is that the continuous elastic structure of the structure is divided into a finite number of small, discrete elements. They are: linear, planar or spatial, with a simple geometric shape, connected to each other at nodal points located along their boundaries. The displacements of these nodal points under the influence of loads applied in them are unknown variables in a system of equations, the solution of which represents the behaviour of the whole structure. In the stress analysis of the problem, these equations are for the static equilibrium of the nodes. The most commonly used two-dimensional finite elements are triangular or quadrangular. The two-dimensional finite elements are used in solving a two-dimensional stress (strain) state.

Modal analysis is used to find out the natural frequencies and mode shapes of a structure. The natural frequencies and mode shapes are extremely significant factor in the design of a structure for dynamic loading conditions. They are also compulsory for a spectrum study or transient study. [5] 
Typically, the type of chatter encountered in turning is of the regenerative type. There has been a great body of work performed on chatter in the last 60 years. Chatter was purported as the result of a negative damping effect. [6]

Both passive damping and active damping methods have been applied to reduce the dynamic response for the bar structure. A passive damping method will be introduced to reduce the structural vibration and dynamic response of the bar in this paper. The constrained layer damping composite bar is a typical passive damping structure which offers an easier and cheaper approach to solve the problem of structural detrimental vibrations. The polyurethane as a viscoelastic material of the damping layer improved the damping property, and the hard metal as a high stiffness material of the constrained layer increased the damping property and compensated the static stiffness. Compared with the bar without the constrained layer damping structure, the damping ratio of the C-P-H composite bar was increased by $400 \%$ and the static stiffness lost $12 \%$.

A study of the literature on the subject found that most of the natural frequencies of vibration and vibrations during the operation of the bar are in the sound range up to $5 \mathrm{kHz}$. [6-10].

Based on the above, the purpose of the study is: Analyzing the impact of the damping system on the natural frequencies of anti-vibration boring bar on a lathe in an environment of Ansys CAE system.

\section{MATERIALS AND METHODS}

To achieve this goal, a Factorial Desing 2-level was made in Minitab. The number of factors is 3. The three factors used are: Weight of the damping elements (X1), the amount of dampering oil (X2) and the diameter of the Orings (X3). The following restrictions are provided for these factors:

$$
\begin{gathered}
80 \leq X 1 \leq 20 \\
5 \leq X 2 \leq 10 \\
2 \leq X 3 \leq 5
\end{gathered}
$$

On the basis of the claimed limitations to the factors in the programming environment is generated a table of 8 experiments (Table.1).

TABLE.1 EXPERIMENTS PLANNING

\begin{tabular}{|c|c|c|c|}
\hline \multicolumn{5}{c|}{ Design Table } \\
\hline Run & X1 & X2 & X3 \\
\hline 1 & + & - & - \\
\hline 2 & + & - & + \\
\hline 3 & + & + & + \\
\hline 4 & - & + & + \\
\hline 5 & - & - & + \\
\hline 6 & + & + & - \\
\hline 7 & - & - & - \\
\hline 8 & - & + & - \\
\hline
\end{tabular}

After experiment planning was made, 3D models of 8 types of boring bar base were designed in SolidWorks environments (Fig.1). For each of them a modal analysis with the CAE Ansys will be performed.

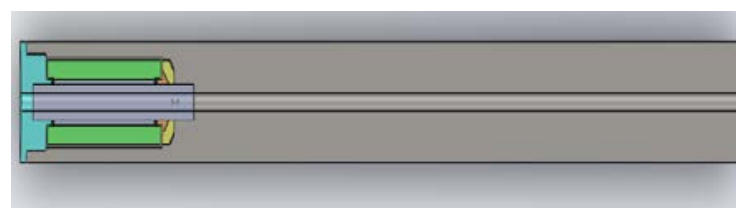

Fig. 1. Section view of boring bar $-\mathrm{X} 1=80 \mathrm{X} 2=5 \mathrm{X} 3=2$

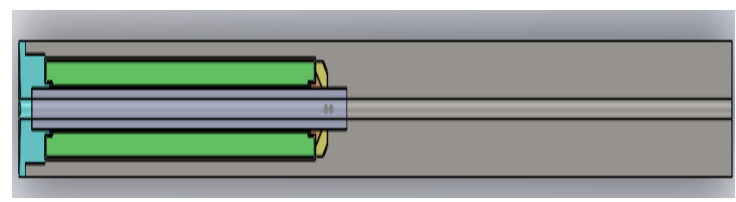

Fig. 2. Section view of boring bar $-\mathrm{X} 1=200 \mathrm{X} 2=5 \mathrm{X} 3=2$

\section{METHOD OF ANALYSIS}

The methodology of the model analysis covers the following events:

$\checkmark$ Preparation of the 3D model of virtual prototype with CAD Protect;

$\checkmark$ Defining the prototype material constants: Young's modulus (elastic module) - $E$; density of the material - $\rho$; Poisson's ratio - $\mu$;

$\checkmark$ Generation of the discretionary calculation model, based on the finite element method;

$\checkmark$ Defining of the restrictive (border) conditions;

$\checkmark$ Selecting the parameters of the numerical results of the modal analysis;

$\checkmark$ Processing of the results - graphically and tabularly.

The following figure represents the boring bar mesh.

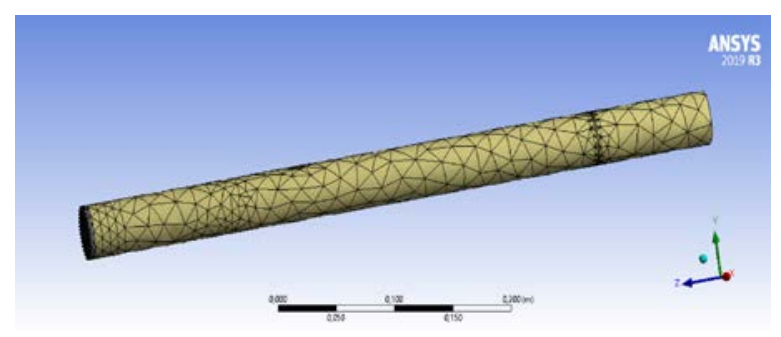

Fig. 3. Mesh

Figure 4 presents the fixe restrain.

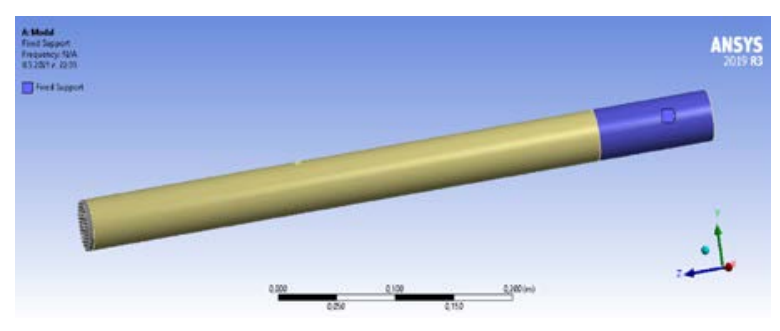

Fig. 4.Fixed restrain 
Environment. Technology. Resources. Rezekne, Latvia Proceedings of the $13^{\text {th }}$ International Scientific and Practical Conference. Volume 3, 310-313

\section{RESULTS AND DISCUSSION}

After the modal analysis has been performed, the natural frequencies were determined for each pattern. The obtained experimental results for the modal frequencies are presented in Table 2.

TABLE 2 NATURAL FREQUENCIES

\begin{tabular}{|c|c|c|c|c|}
\hline Run & $\begin{array}{c}\mathbf{X 1} \\
{[\mathbf{m m}]}\end{array}$ & $\begin{array}{c}\mathbf{X 2} \\
{[\mathbf{m m}]}\end{array}$ & $\begin{array}{c}\mathbf{X 3} \\
{[\mathbf{m m}]}\end{array}$ & $\begin{array}{c}\mathbf{y} \\
{[\mathbf{H z}]}\end{array}$ \\
\hline 1 & 80 & 5 & 2 & 501 \\
\hline 2 & 200 & 5 & 2 & 860 \\
\hline 3 & 80 & 10 & 2 & 274 \\
\hline 4 & 200 & 10 & 2 & 536 \\
\hline 5 & 80 & 5 & 5 & 390 \\
\hline 6 & 200 & 5 & 5 & 878 \\
\hline 7 & 80 & 10 & 5 & 274 \\
\hline 8 & 200 & 10 & 5 & 520 \\
\hline
\end{tabular}

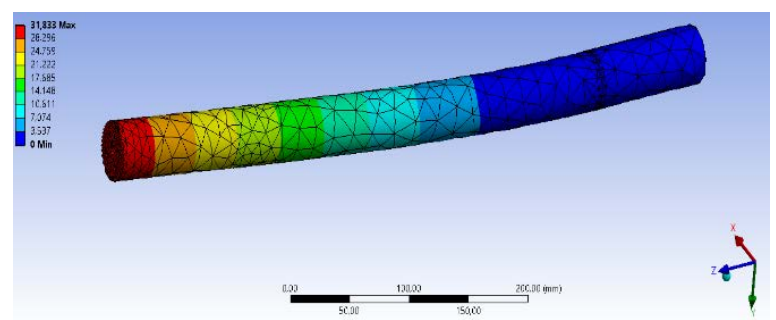

Fig. 5. Mode shape at $501 \mathrm{~Hz}$

The mathematical and statistical processing is made with the MINITAB 17. The regression equation is shown as follow:

$$
\begin{aligned}
y= & 253+4,942 X 1-11,7 X 2- \\
& -9,08 X 3-0,2825 X 1 * X 2
\end{aligned}
$$

TABLE 3 COEFFICIENTS

\begin{tabular}{|l|r|r|c|r|r|r|}
\hline erm & Coef & SE Coef & $\mathbf{9 5 \%}$ Cl & T-Value & P-Value & VIF \\
\hline Const & 253 & 120 & $(-129 ; 636)$ & 2,11 & 0,126 & \\
\hline $\mathrm{X} 1$ & 4,942 & 0,758 & $(2,529 ; 7,354)$ & 6,52 & 0,007 & 10,00 \\
\hline $\mathrm{X} 2$ & $-11,7$ & 14,6 & $(-58,2 ; 34,8)$ & $-0,80$ & 0,482 & 6,44 \\
\hline $\mathrm{X} 3$ & $-9,08$ & 9,59 & $(-39,60 ; 21,43)$ & $-0,95$ & 0,413 & 1,00 \\
\hline $\mathrm{X} 1{ }^{\star} \mathrm{X} 2$ & $-0,2825$ & 0,0959 & $(-0,5877 ; 0,0227)$ & $-2,95$ & 0,060 & 15,44 \\
\hline
\end{tabular}

TABLE 4 MODEL SUMMARY

\begin{tabular}{|r|r|r|r|r|r|r|}
\hline $\mathbf{S}$ & R-sq & R-sq(adj) & PRESS & R-sq(pred) & AICc & BIC \\
\hline 40,6832 & $98,70 \%$ & $96,96 \%$ & 35309,3 & $90,75 \%$ & 170,15 & 86,63 \\
\hline
\end{tabular}

TABLE 5 ANALYSIS OF VARIANCE

\begin{tabular}{|l|r|r|r|r|r|r|r|}
\hline Source & DF & Seq SS & Contribution & Adj SS & $\begin{array}{r}\text { Adj } \\
\text { MS }\end{array}$ & $\begin{array}{r}\text { F- } \\
\text { Value }\end{array}$ & $\begin{array}{r}\text { P- } \\
\text { Value }\end{array}$ \\
\hline Regression & 4 & 376681 & $98,70 \%$ & 376681 & 94170 & 56,90 & 0,004 \\
\hline X1 & 1 & 229503 & $60,13 \%$ & 70330 & 70330 & 42,49 & 0,007 \\
\hline X2 & 1 & 131328 & $34,41 \%$ & 1062 & 1062 & 0,64 & 0,482 \\
\hline X3 & 1 & 1485 & $0,39 \%$ & 1485 & 1485 & 0,90 & 0,413 \\
\hline X1*X2 & 1 & 14365 & $3,76 \%$ & 14365 & 14365 & 8,68 & 0,060 \\
\hline Error & 3 & 4965 & $1,30 \%$ & 4965 & 1655 & & \\
\hline Total & 7 & 381647 & $100,00 \%$ & & & & \\
\hline
\end{tabular}

F - value of the Fischer' distribution used to verify the significance of the coefficient of a multiple correlation;

P - Multiple correlation coefficient. The multiple correlation coefficient is insignificant if $P>\alpha(\alpha=0.05)$

The analysis of the residuals does not show disruption of the prerequisites for the regression analysis. On Fig. 6 it can be seen that all residuals are within the range \pm 2 . Therefore, a conclusion can be made that there are no errors.

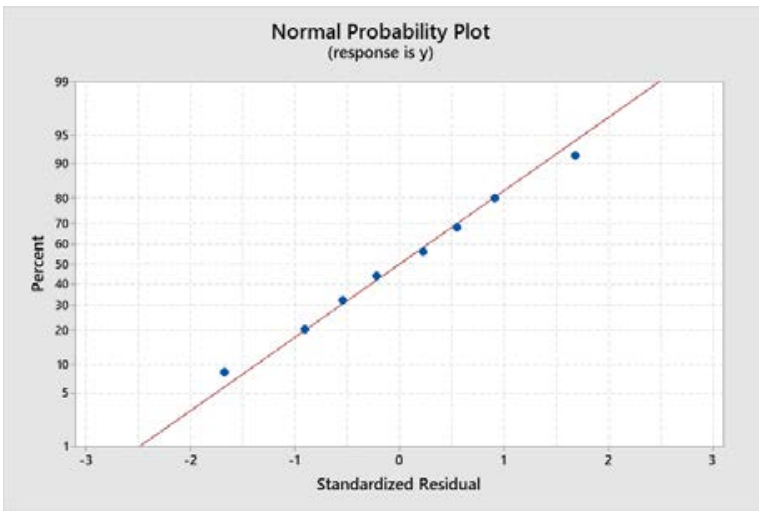

Fig. 6. Standardized Residual

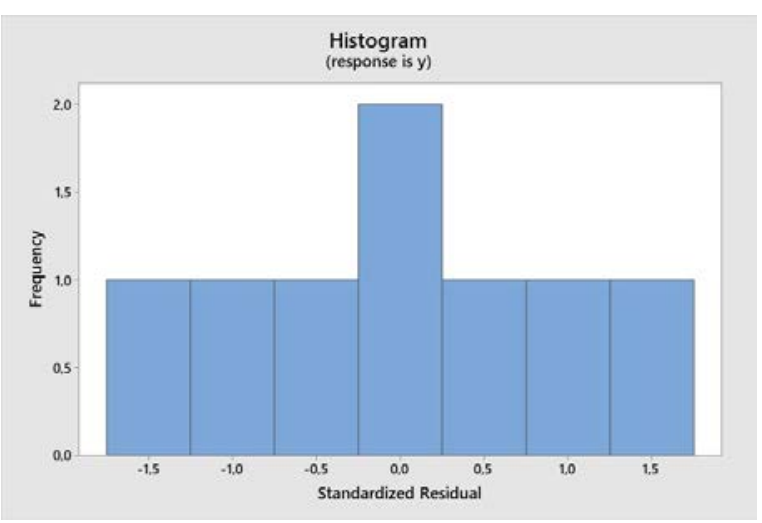

Fig. 7.Standardized Residual

Based on the regression model, the design of the antivibration bar was optimized. A minimum natural frequency was chosen for the optimization goal.

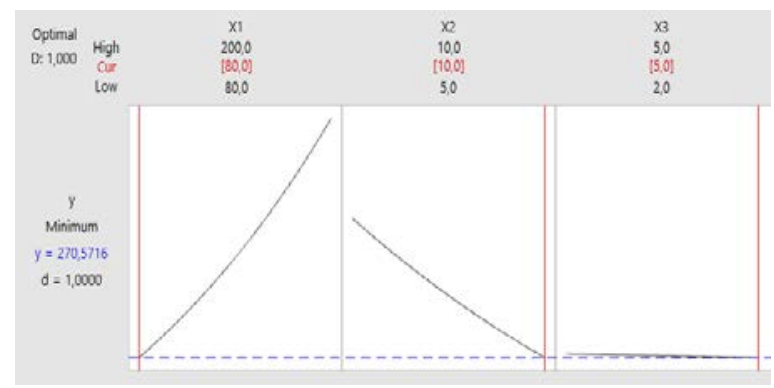

Fig. 8. Factorial Plots 


\section{CONCLUSIONS}

The results of this work are summarized as follows:

- Theoretical and methodological presentation of the stages for conducting the analysis was performed through CAE systems for engineering calculations, simulations and analysis of details of an antivibration bar.

- A virtual prototype of an anti-vibration bar has been generated on SolidWorks CAD system.

- A dynamic simulation analysis has been performed using the finite element method (FEM) of an antivibration boring bar.

- Quantitative values were obtained for the natural frequencies of the model.

The optimization results show that the amount of damping oil and the length of the damping element have the most significant influence on the natural frequencies.

As it can be seen from Fig. № 8, by increasing the damping oil, the natural frequencies of the rod decrease, and conversely, by increasing the length of the damping element, the frequency increases.

Acknowledgments: The authors would like to thank the Research and Development Sector at the Technical University of Sofia for the financial support.

\section{REFERENCES}

[1] Zlatanov, Z. C., Ruschev, D. T., Raychev, R. P., Tashev, I. I., Determination natural frequency of beam with boundary element method , pp. 23-26, 2011, Bulgaria, ISBN ISSN1311-9192.

[2] Atsushi M, Minetaka M, Iwao Y, Vibration suppression of boring bar by piezoelectric actuators and LR circuit, 2014 Ann CIRP
Manuf Technol 1243:619-642

https://doi.org/10.1016/j.cirp.2014.03.132

[3] Lu XD, Chen F, Altintas Y, Magnetic actuator for active damping of boring bars, 2014, Ann CIRP Manuf Technol 1238:771-774 https://doi.org/10.1016/j.cirp.2014.03.127

[4] R. Vinayaravi, D.Kumaresan, K.Jayaraj, A.K.Asraff R.Muthukumar, Experimental investigation and theoretical modelling of an impact damper, Journal of Sound and Vibration Volume 332, Issue 5, 4 March 2013, Pages 1324-1334 https://doi.org/10.1016/j.jsv.2012.10.032

[5] Singaravelu Chockalingam, Ramabalan S., Govindan K., Chatter control and stability analysis in cantilever boring bar using FEA methods, MaterialsToday: Proceedings Volume 33, Part 7, 2020, Pages 2577-2580 https://doi.org/10.1016/j.matpr.2019.12.166

[6] Adam.A. Cardi, H.A. Firpi, M.T. Bement, S.Y. Liang, Workpiece dynamic analysis and prediction during chatter of turning process, Mech. Syst. Signal Process., 22 (2008), pp. 1481-1494 https://doi.org/10.1016/j.ymssp.2007.11.026

[7] Mohit Law, Pulkit Gupta, Suparno Mukhopadhyay, Modal analysis of machine tools using visual vibrometry and output-only methods, CIRP Annals, Volume 69, Issue 1, 2020, Pages 357-360 https://doi.org/10.1016/j.cirp.2020.04.043

[8] Mohsen Fallah, Behnam Moetakef-Imani, Ali Hosseini, Mostafa Ebrahimi, Boring Bar Chatter Control using Feedback Filtered-x Normalized Least Mean Square Algorithm, IFAC-Papers On Line, Volume 52, Issue 10, 2019, Pages 358-363. https://doi.org/10.1016/j.ifacol.2019.10.057

[9] Yang Bu, Zhanqiang Liu, Reduction of dynamic response of a bar using constrained layer damping composite structure, September 2018 Journal of Physics Conference Series 1074(1):012009 https://iopscience.iop.org/article/10.1088/17426596/1074/1/012009

[10] Tatiana Smirnova, Henrik Akesson ,Lars Hakansson, Modeling of an Active Boring Bar, December 2007

[11] Sentyakov, Kirill; Peterka, Jozef; Smirnov, Vitalii; Bozek, Pavol; Sviatskii, Vladislav. 2020. "Modeling of Boring Mandrel Working Process with Vibration Damper" Materials 13, no. 8: 1931. https://doi.org/10.3390/ma13081931 